\title{
A Profile of the Burnout Construct Amongst Teachers: Evidence from Four Senior Secondary School in Botswana
}

\author{
Molefhe Mogapi \\ University of Botswana, Faculty of Education, Department of Educational Foundations \\ molefhe.mogapi@mopipi.ub.bw \\ Fazlah Moorad \\ MOORADF@mopipi.ub.bw \\ University of Botswana, Faculty of Education, Department of Educational Foundations.
}

\begin{abstract}
.
The burnout construct has attracted the attention of researchers in many countries because of its negative effects on the learning and teaching process. Teachers experiencing burnout are characterized by high levels of emotional exhaustion resulting from intense and consistent pressure from demand stressors in the work place. Persistence of these stressors leads to depersonalization of learners and ultimately reduced personal accomplishments. The current study examined the burnout construct amongst secondary school teachers in Botswana and linked its implications to professional competence of teachers. The study used the Maslach and Jackson three dimension conceptualization of the construct. Findings from the study indicated that teachers were experiencing relatively high levels of emotional exhaustion. There were also signs that some teachers were progressing towards the depersonalization and reduced personal accomplishment stages of the construct. A recommendation was tendered to the effect that a large scale study should be conducted to determine the number of teachers who are at risk of developing all three indictors of the syndrome.
\end{abstract}

Key words: Burnout syndrome, depression, factor structure, locus of control, cynicism, self-efficacy.

DOI: $10.7176 / \mathrm{JEP} / 11-30-16$

Publication date:October $31^{\text {st }} 2020$

\subsection{Introduction}

In Botswana, several studies have indicated the possible existence of burnout syndrome amongst teachers. For example, Isaiah and Nenty (2012) conducted a study that sought to determine predictors of job dissatisfaction amongst junior secondary school teachers. The two researchers in the end posited that:

A disgruntled worker cannot put in assiduous effort at achieving set goals, especially goals whose levels of achievement are not readily obvious. The spirit underlying the natural pride of contributing to the growth and development of human beings is greatly robbed by the dissatisfaction among teachers ( $p$. 277).

Pheko, Mosothwane and Segomotsi (2015) also conducting a study to specifically determine factors that prevented teachers from effectively discharging their duties with the school. The sample of the study comprised 50 participants randomly selected from a target population of 500 secondary school teachers. Analysis of the items indicated that $66 \%$ of the teachers were unhappy with their accommodation facilities while $77 \%$ considered the class size within their schools to be unmanageable. As an indication of depersonalization, $65 \%$ of the respondents stated that they were no longer sympathetic to other teachers and students. Additional empirical evidence relating to the emerging problem of stress in schools was provided by Baliyan, Baliyan and Mokoena (2018). The objective of the study was to identify main causes of stress amongst private senior secondary school teachers. Teachers who responded to the survey instrument listed 10 major causes of stress; these included school policies, work load, pupil indiscipline, dealing with mixed ability classes and lack of parental involvement. A high level of stress was associated with low morale, loss of concentration, absenteeism, chronic disease and drug abuse (Baliyan, Baliyan, \& Mokoena, 2018). Therefore, emerging literature on the wellbeing of the teachers is pointing towards existence of factors in schools that may eventual lead to burnout. More studies are needed to provide empirical evidence on the nature and dynamics of burnout amongst teachers so that appropriate intervention strategies could be put in place. 


\subsection{Background to the study}

Professionals dealing directly with people and their problems do not always manage to resolve such issues resulting in the development of a highly charged interpersonal relationship between the service provider and the client (Larrivee, 2012). If this condition continues for a considerable period of time and is perceived by the helpgiver as being a threat, then the person develops stress (Maslach, Jackson, \& Leiter, 1997; Smetackovaa, 2019). The stress effect would necessarily prevent the person from executing his/ her duties effectively and efficiently thus transforming into burnout (Brissie, Hoover-Dempsy, \& Bassler, 1988; Farber, 1984; Smetackovaa, 2019). As a result, burnout is intricately related to stress and depression. According to Sarros \& Sarros (1987), a certain amount of tress is necessary as it urges people to apply themselves more in the work place. It promotes healthy competition between co-workers and it may also be a source of intrinsic motivation as the worker pushes to do more on every day basis. According to Maslach, Jackson, and Leiter (1997), burnout;

$\ldots$ is an individual stress experience embedded in a context of complex social relationships and that it involves the persons conception of both self and others. To look simply at the stress component of this experience is not enough, because it ignores the two latter components of self-evaluation and relation to others (p. 204).

Depression is another factor that might be confounded with burnout making it important to draw a clear conceptual distinction between the two concepts. Depression has been characterized as a clinical syndrome whereas burnout describes a crisis in one's relationship with work, especially the therapeutic relationship with service recipients (Maslach, Jackson, \& Leiter, 1997, pp. 202-203). The authors go on to state that depression affects every aspect of a person's everyday life. Burnout, on the other hand, is mostly confined to occupational interpersonal relationships. The teaching profession has been shown to be particularly susceptible to stress and burnout (Arvidsson, Larsson, Hakansson, Persson, \& Björk, 2019; Brasfield, 2019; Johnson, Cooper, Cartwrights, Donald, Taylor \& Millet, 2005). Initially, studies tended to link burnout to a number of teacher personality characteristics such as age, sex, marital status, socio-economic status. This approach was heavily criticized for putting all the blame on the teacher. According to Dorman (2003), "For too long, teacher burnout has been explained largely in terms of individual teacher personality characteristics' (p. 45). A number of research studies thus emerged treating school environmental variables as principal predictors of burnout (e.g.,Tosi \& Tosi, 1970; Weiskopt, 1980). However, the two camps eventually merged when researchers integrated personality and institutional factors in one study.

The interactive effect of personality and institutional variables was demonstrated by Brissie, HooverDempsy, and Brassler (1988) study. The researchers applied a multiple stepwise regression to assess the predictive power and relative importance of teacher level variables and institutional factors. The full model accounted for $44 \%$ of the variance in the burnout scores and the highest ranking variables in terms of beta weights were "teacher perceptions of internal rewards, organizational rigidity, and principal support" (Brissie, Hoover-Dempsy, and Brassler, 1988, p. 110). Suffice to mention at this juncture that theoretical understanding of the burnout construct continues to improve as more studies are done all over the world. For example, Chang (2009) proposed that transactional factors (i.e., the interaction between personality and organizational variables) should also be considered as significant causes of burnout. Recently, Kim, Jörg \& Klassen (2019) explored the relation between personality domains (openness, conscientiousness, extraversion, agreeableness, and emotional stability) and burnout. Interest in burnout is mostly fuelled by the research evidence that consistently link the syndrome to internal and external locus of control (e.g., Scott, 2019), self efficacy (e.g., Smetancokvaa, 2019), school social support systems (e.g., Farber, 1984), and high levels of teacher attrition (e.g., va Zyl, 2015).

Teacher burnout and Locus of Control

Research studies have been able to establish that teachers respond to stress differently as a function of their locus of control. Teachers with an internal locus of control believe that they can respond to adverse environmental factors in a way that mitigates the effects of the stressors (Lunenburg \& Cadavid, 1992). This group of teachers often presents lower levels of reported stress (Bevis, 2008). On the other hand, teachers who feel that they are not entirely in control of what is happening around them are said to be exhibiting external locus of control (Kormanik \& Rocco, 2009). A study done by Bevis (2008) established a moderate correlation between locus of control and burnout scores. The findings were later corroborated by Bitsadze and Japaridze (2016). The two authors posited that "...teachers having external locus of control, are more prone to emotional exhaustion than teachers having internal locus of control (p. 12). Studies have also demonstrated positive covariance between Locus of control and self efficacy measures. Smetancokvaa (2019) defines self efficacy as "as the teacher's beliefs in his/her own ability to plan, organize, and carry out different educational activities that are essential for achieving pedagogical goals" (p. 2477). A number of studies have shown that teachers scoring high on self efficacy measures consistently report low burnout scores (Smetancokvaa, 2019; Skaalvik \& Skaalvik, 2007). Specifically, emotional 
exhaustion and depersonalization are negatively correlated with self efficacy (Skaalvik \& Skaalvik, 2010). Teachers reporting high self-efficacy are committed to their work and use innovative teaching strategies to improve the academic performance of their learners. Thus, burnout erodes the teacher's professional competence and has a negative impact of educational outcomes.

Teacher burnout and Social Support

According to Uzun (2018), "Among the variables affecting the attitudes and behaviours of the teachers are the managerial behaviours of the school administrators. Positive and negative managerial behaviours of school administrators can affect how teachers behave in working life" (p. 501). It is the singular responsibility of school administrators to make sure that teachers are engaged fully in the day to day running of the school. If teachers feel that their ideas are appreciated and valued by the principal (Burns, 2016), they tend to develop cognitive and emotional attachment to the institution (Rikette, 2005). Social support emerged as a significant predictor of burnout in a study conducted by Farber (1984). Out of a sample of 398 school teachers, $63.4 \%$ reported that "... they rarely or never received support or encouragement from their principal” (p. 328). The influence of social support was also confirmed by Russell et al. (1987). The researchers sampled 660 elementary and secondary school teachers in Iowa, USA; analysis of the data indicated that "Teachers with supportive supervisors reported less emotional exhaustion, more positive attitude toward students, and greater personal accomplishment" (p. 271). Supportive school administrators do not only inculcate positive attitude and a sense of belonging amongst their teachers but also help teachers deal effectively with potential stressors in the work place such as role ambiguity, disruptive learners and work overloaded. These stressors, if left unattended, have the potential to create an environment that is not conducive for effective learning and teaching.

Burnout Syndrome and Teacher Attrition

According to Scott (2019); "Teacher attrition has become a significant problem within the field of education" (p. 2). In Australia, a study by Goddard and Goddard (2006) showed that 21\% of the surveyed teachers were seriously considering leaving the teaching profession. Similar results were later uncovered by va Zyl (2015); the researcher recorded a strong and significant correlation between cynicism and turnover intentions. In other words, teachers experiencing high levels of depersonalization had strong intentions to leave the teaching profession. Therefore, burnout does not only contribute towards low productivity and reduced instructional effectiveness in schools ( $\mathrm{Li}$ et al., 2020) but also robs the profession of the most creative and innovative practitioners. In summary, the long term effect of burnout on the individual teacher is a gradual reduction in efficiency and productivity (Maslach et al., 2001) culminating in a concomitant decline in learner performance indicators and the quality of education. It is the responsibility of different stakeholders in the education sector to develop and implement strategies that will mitigate the adverse effect of burnout in schools..

\subsection{Theoretical Framework}

The construct of burnout is conceptualized as having three related but psychometrically distinct dimensions; namely, emotional exhaustion, depersonalization, and reduced personal accomplishment (Li et al., 2020). According to several published research, emotional exhaustion is the initial stage that is engendered by prolonged exposure to demand stressors in the workplace (Capel, 1987; Dubale et al., 2019). Depersonalization develops as the emotionally exhausted teacher tries to find ways and means of coping with the ever increasing levels of stress (Polatcan, Cansoy \& Kilınç, 2019). Depersonalization is characterized by development of a negative and uncaring attitude towards recipients of the services provided by the teacher (i.e., students and parents). As such, depersonalization is regarded as a dysfunctional coping strategy since the person concerned tries to break his or her relationship with service recipients (Maslach, Schaufeli \& Leiter, 2001). The negativity, cynicism and poor interpersonal relationship associated with a depersonalised self makes the teacher to doubt his or her effectiveness on the job. Low self-esteem then characterises the reduced personal accomplishment dimension. Therefore, emotional exhaustion and depersonalization are inversely related to personal accomplishment as indicated in Figure 1. 


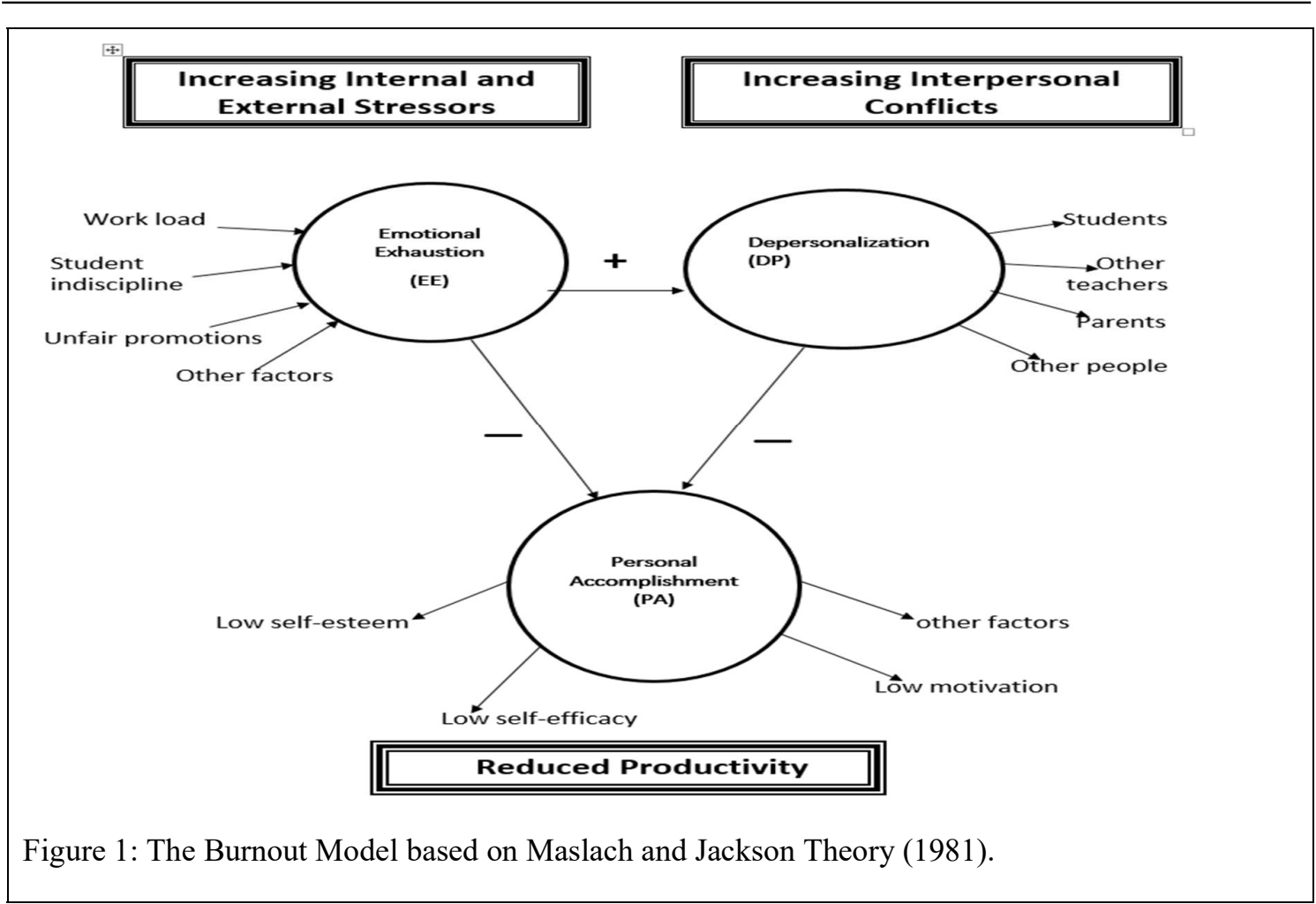

\subsection{Statement of the problem}

High levels of experienced burnout amongst teachers is a serious cause for concern for all stakeholders in the educational system because burnout has been shown to be a significant predictor of high rates of absenteeism, turnover, poor interpersonal relationship and declining academic performance. As the work induced stress levels increase and persist for a long period of time, the teacher becomes emotionally and physically strained. The emotional exhaustion negatively affects the teacher's teaching self-esteem leading to low productivity levels. Teachers should be motivated all times so that they feel part and parcel of the organization and are fairly rewarded with personal and professional advancement. If the problem of high levels of experienced burnout is not tackled urgently and decisively, the morale of the teachers as well as their teaching self-efficacy will be negatively impacted.

\subsection{Purpose of the study}

The purpose of the study is to test the data obtained from a sample of secondary school teachers for item clustering consistent with the burnout construct. Therefore, the main research question for the study is: "Will the data obtained from a sample of secondary school teachers indicate presence of the three burnout dimensions?" Significant loading of items on their predicted factors will be a strong indicator of presence of burnout syndrome in the parent population.

\subsection{Literature Review}

The burnout syndrome is now considered to be a global health problem (Kerry-Henkel, 2019) and as such it is imperative that researchers in different parts of the world conceptualize the construct in ways that are comparable. Similar operationalization of the construct will help to bring consistency in the way researchers collected and analyze data.

Construct validation of the MBI scale

One instrument that has promising international appeal is the MBI (Maslach, Jackson, \& Schwab, 1996). Several studies have been conducted to validate the psychometric efficacy of the scale (Byrne, 1984; Iwanicki \& 
Schwab, 1981; Jackson \& Rothman, 2005). For example, Iwanicki and Schwab (1981) used data from 469 Massachusetts teachers to examine the construct validity of the MBI questionnaire. The factor structure obtained was largely consistent with the multidimensional conceptualization of burnout. An argument is support MBI construct validity was also tendered by Dorman (2003). A total of three individual variables (i.e., teaching efficacy, external locus of control and self-efficacy) and six organizational predictors (i.e., role overload, classroom environment, role conflict, role ambiguity, work pressure and school environment) were included in the model together with the three burnout dimensions. The proposed three factor model fitted the data very well (Dorman, 2005).

Confirming the burnout syndrome amongst a population of teachers

The MBI scale has been used to investigate teacher burnout in Canada (Sarros \& Sarros, 1987), Greece (Tsigilis, 2011), China (Li et al., 2020), Nigeria (Okwaraji and Aguwa, 2015) and Namibia (Louw \& Esterhuyse, 2011). Sarros and Sarros (1987) run a study to determine the factor structure of the burnout construct amongst a sample of teachers and school administrators in Canada. Teachers reported higher levels of emotional exhaustion and depersonalization as compared to school administrators. The explanation provided was that teachers were more exposed to disruptive behaviour emanating from learners in the classroom. In Greece, a study by Tsigilis (2011) established that teachers in primary schools were more emotionally exhausted than their secondary schools counterparts. Previous studies indicated that large classrooms and learner indiscipline were amongst the most prominent work stressors for Greek teachers (Antoniou et al. (2006). Li et al. (2020) used a relatively large sample (1741 participants) to investigate the prevalence of burnout amongst pre-school teachers in China. A total of 673 $(38.6 \%)$ teachers reported low levels of emotional exhaustion and $415(23.8 \%)$ were showing signs of depersonalization. Reduced personal accomplishments category recorded a total of $382(21.8 \%)$ teachers. On average, $53.2 \%$ of the surveyed teachers were categorized as experiencing burnout.

Teachers in the African continent have also been exposed to the burnout syndrome. Okwaraji and Aguwa (2015) sampled 432 secondary school teachers in Enuga State (Eastern Nigeria). The study established that “...40\% of the teachers were emotionally exhausted, $39.4 \%$ showed depersonalization while $36.8 \%$ manifested reduced personal accomplishments ...” (p. 484). A research study by Louw and Esterhuyse (2011) investigated the presence of self-reported burnout amongst secondary school teachers in Namibia. The researcher administered the Maslach Burnout Inventory (MBI) to a total of 480 teachers sampled from 17 state schools. Approximately, a quarter of the teachers in the sample experienced high levels of emotional exhaustion, whilst $12.2 \%$ experienced high levels of depersonalisation.. In Botswana, several studies were done to identify predictors of teacher dissatisfaction and causes of stress in schools (Baliyan, Baliyan, \& Mokoena, 2018; Isaiah \& Nenty, 2012; Pheko, Mosothwane, \& Segomotsi, 2015). However, there is no study that used the Maslach Burnout Inventory scale (MBI) (Maslach, Jackson \& Schwab, 1996) to inves tigate the teacher burnout construct. The MBI has been validated across different populations and has well known psychometric properties (Kerry-Henkel, 2019).

\subsection{Methodology}

The quantitative approach was used to provide answers to the research question. To achieve this objective, a survey design was used where questionnaires were administered to a sample teachers. The population of the study came from four purposively selected senior secondary schools in the southern part of Botswana. The four schools had a combined population of around 400 teachers. The questionnaires were administered over a period of two months in 2019; the final sample comprised 149 teachers. The MBI scale has 22 Likert items divided into three subscales; emotional exhaustion ( 9 items), depersonalisation (5 items) and reduced personal accomplishments ( 8 items). The scale of the questionnaire ranges from 0 (minimum score) to 6 (maximum score). All the teachers sampled were given the opportunity to state whether they agreed or disagreed to be part of the study and only those with a positive response were included in the final sample. No personal details of the teachers were indicated on the questionnaire and teachers were specifically informed that the questionnaire was not being used as a diagnostic tool. Before the study commenced, permission was sought from University of Botswana Institutional Review Board (IRB); IBR is responsible for making sure that all pertinent ethical issues are applied satisfactorily at all stages of the research project.

\subsection{Data Presentation and Analysis}

The 149 MBI questionnaires were analyzed using SPSS version 25 to extract intercorrelation coefficients, Kaiser-Meyer-Olkin (KMO) and Bartlett's test of sphericity indicators, reliability index, factor loadings and scree plot. The analysis produced a reliability index of .59 meaning that the burnout construct explains $34 \%$ of the variance in the data. 
Does the correlation matrix indicate presence of the burnout dimensions?

Factor extraction. Factor analysis was applied to identify the number of underlying item clustering. The factorability of the matrix extracted using principal component analysis with Varimax rotation techniques produced a KMO value of .611 and the Bartlett's test of sphericity was significant. The Kaiser criterion (Kaiser, 1960) indicted existence of seven factors with eigenvalues greater than 1 . Table 1 shows that Factor 1 explained $48.257 \%$ of the variance in the matrix while Factor 2 and Factor 3 accounted for $15.876 \%$ and $11.811 \%$ of the variance in the data. Taken together, the three factors account for $75.944 \%$ of the variance. The scree plot (Figure 2) had two inflection points; the first inflection produced three factors while the second one confirmed five factors. However, the last four factors suggested by Kaiser criterion were only indicated by one item each and thus lacked substantive meaning. Taken together, the Kaiser criterion and the scree plot point to three underlying item clustering points or dimensions.

\section{Table 1: Variance explained by Each Extracted Factors}

\begin{tabular}{|llll|}
\hline Component & Total (\%) & Variance Explained (\%) & $\begin{array}{l}\text { Cumulative of Variance } \\
\text { Explained (\%) }\end{array}$ \\
\hline 1 & 408.799 & 48.257 & 48.257 \\
2 & 134.489 & 15.876 & 64.133 \\
3 & 100.055 & 11.811 & 75.944 \\
$(4)$ & 71.359 & 8.424 & \\
$(5)$ & 69.314 & 8.182 & \\
$(6)$ & 21.219 & 2.505 & \\
$(7)$ & 9,465 & 1.117 & \\
\hline
\end{tabular}

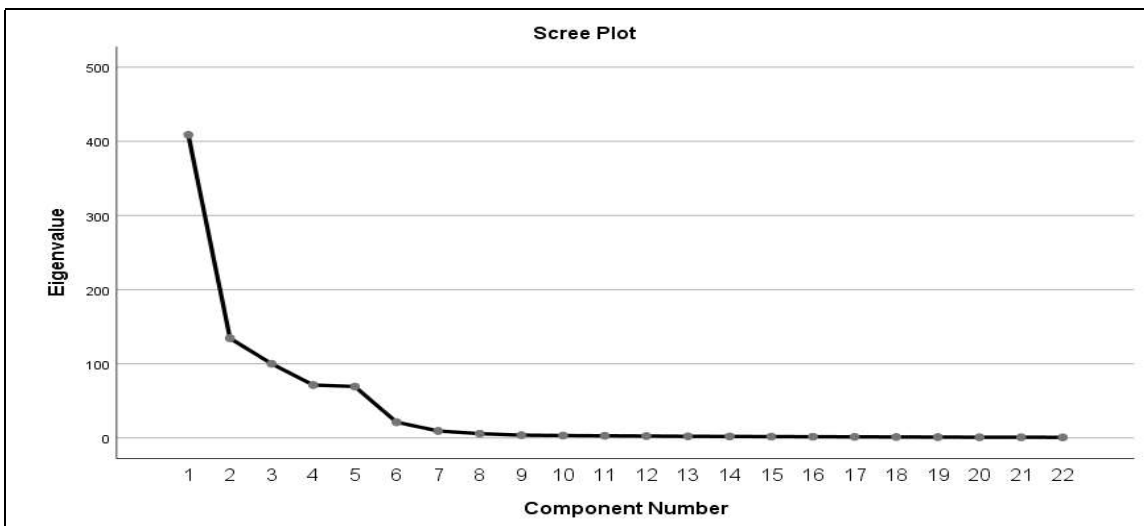

Figure 2: Scree Plot Showing Two Inflection Points 
Table 2: Emotional Exhaustion Item Frequencies

\begin{tabular}{|c|c|c|c|c|c|c|c|c|c|}
\hline & $\begin{array}{l}\text { Item } \\
1\end{array}$ & $\begin{array}{l}\text { Item } \\
2\end{array}$ & $\begin{array}{l}\text { Item } \\
3\end{array}$ & $\begin{array}{l}\text { Item } \\
6\end{array}$ & $\begin{array}{l}\text { Item } \\
8\end{array}$ & $\begin{array}{l}\text { Item } \\
13\end{array}$ & $\begin{array}{l}\text { Item } \\
14\end{array}$ & $\begin{array}{l}\text { Item } \\
16\end{array}$ & $\begin{array}{l}\text { Item } \\
20\end{array}$ \\
\hline Median & 3 & 3 & 3 & 1 & 3 & 3 & 5 & 1 & 1 \\
\hline $\begin{array}{l}\text { Maximum } \\
\text { score }\end{array}$ & 6 & 6 & 6 & 6 & 6 & 6 & 6 & 6 & 6 \\
\hline Mean & 3.6383 & 3.0496 & 3.0213 & 2.2340 & 3.5603 & 3.0851 & 5.1206 & 1.8014 & 2.5957 \\
\hline
\end{tabular}

Item intercorrelations. The intercorrelation indexes for the emotional exhaustion items were largely in the expected directions. For example, the first item of the scale (I feel emotionally drained from my work) correlated positively with items that belonged to the emotional exhaustion subscale. This item was positively related to Item 3 (I feel fatigued when I get up in the morning and have to face another day on the job), Item 6 (Working with people all day is a strain for me), Item 2 (I feel used up at the end of the workday), Item 14 (I feel I'm working too hard on my job), and Item 20 (I feel I'm at the end of my rope).The same item (i.e., Item 1) was negatively related to Item 4 (I can easily understand how my students feel about things), Item 9 (I feel I'm positively influencing other people's lives through my work), Item 17 (I can easily create a relaxed environment with my students) and Item 21 (In my work, I deal with emotional problems very calmly). The fact that emotional exhaustion items correlate positively amongst themselves and negatively with items targeting other dimensions is evidence of construct validity of the subscale.

Frequency means scores. The average mean score for the emotional exhaustion component was 3.1 indicating that teachers feel emotionally exhausted a few times per month. Table 2 shows that Item 14 recorded the highest mean frequency of 5.1206 with a median score of 5. This was followed by Item 1 and Item 8 with mean frequency scores of 3.6383 and 3.5603. The next group of items with high frequencies were Item $13(\mathrm{Mean}=$ $3.051)$, Item $2($ Mean = 3.0496) and Item $3($ Mean =3.0213). The depersonalization subscale had a mean frequency score of 2.0 implying that teachers feel having a cynical attitude towards students and other people within the school a few times a year. On the other hand, the personal accomplishment subscales mean scores was the highest at 4.4. Noting that higher values for the personal accomplishment subscale indicates positive dispositions or low burnout, this value shows that generally teachers still have a positive personal accomplishments dispositions. Therefore, the analysis pointed towards a strong presence of the emotional exhaustion dimension in the data. There was also evidence of emergence of two additional dimensions to make a total of three factors; however, the two dimensions were not strongly represented in the data.

\subsection{Discussion of Findings}

The analysis indicated a moderate reliability for the MBI scale when administered to a sample of teachers in Botswana. Previous research studies in the literature have recorded higher values for all subscales. For example, 
MBI reliability scores reported by O'Brien, Goddard, and Keeffe (2008) were .92 (EE), .79 (DP), and .79 (PA). The current index of .6 can be taken to be satisfactory looking at the size of the sample (i.e., 149 teachers). The Kaiser criterion and scree plot techniques were used to extract underlying dimensions in the data. The scree plot suggested a maximum of five factors. The five factor solution was consistent with findings from previous research studies (e.g., Firth, Mckeown, \& Britton, 1985; Iwanicki \& Schwab, 1981; Kanste, Miettunen, \& Kyngas, 2006). However, the five factor solution was not theoretically appealing because the last two factors in the list were indicated by few items. These factors were eliminated basing on the reasoning that a factor should explain more variance than an individual item. This rule avoids a situation where the number of factors extracted will be equal to the number of items used in the analysis. Implementation of this rule led to the extraction of three factors. The three selected factors accounted for $75.944 \%$ of the variance in the data. A number of studies in the literature have also settled for a three factor solution (e.g., Byrne, 1991; Byrne, 1993; Green \& Walkey, 1988; Gold, 1984; Holland \& Kim, 1994).

The first factor to be extracted was consistent with emotional exhaustion dimension as suggested by Maslach and Jackson (1981). The naming of the factor was based on evidence from the literature suggesting that emotional exhaustion emerges first in the analysis (Byrne, 1994; Dormen, 2003). Secondly, majority of items loading significantly on the factor were designed to tap on the emotional exhaustion experiences of teachers. The other two factors (i.e., depersonalization and personal accomplishments), though contributing significantly to the amount of variance explained in the data, were not clearly represented. At least two points are responsible for this state of affairs. Firstly, several items belonging to the two factors loaded on more than one factor. Cross loading items were also observed in a number of previous EFA studies. A study by Gold, Bachelor, and Michael (1989) showed that Item 11 cross loaded between emotional exhaustion and depersonalization subscales. The cross loading of item 11 was also confirmed by Aluja, Blanch and Garcia (2005). Secondly, the sample used in the study was relatively small when compared to samples used in other factor analysis studies. For example, Jackson and Rothmans (2005) used 1177 teachers while Li et al. (2020) sampled 1741 participants. Using a small sample appears to have enhanced the influence of error variance in the analysis. Factor analysis is essentially a large sample technique; large samples allow systematic variance in the data to have more influence on the correlation patterns. Different rules of thumb have been developed to assist researchers determine the minimum number of participants required for conducting factor analysis. Cattell (1978) suggested a minimum sample of 250 participants while Comrey and Lee (1992) advised researches to obtain samples of at least 500 respondents.

\subsection{Conclusion}

A conclusion can be tentatively drawn that the burnout syndrome is present amongst the sampled teachers. However, only emotional exhaustion dimension has clearly developed and is indicated by items that are theoretically related to the component. The other two dimensions are less clearly defined. Taking into consideration that the burnout syndrome starts with teachers consistently experiencing stressful situation at work (Leiter \& Maslach, 1988), the evidence could be indicating that teachers in Botswana are at the initial stage of burnout. Conditions have not as yet led to the crystallization of depersonalization and feelings of reduced personal accomplishments. If the demand stressors are not identified and neutralized, then the teachers will slowly progress towards depersonalization and reduced personal accomplishments stages of burnout. There is evidence in the data indicating that some teachers are already showing depersonalization and inefficacy signs. According to Jacobson (2016), "Burnout creates a social crisis that impacts not only teachers; it also affects students, both academically and socially. The problem will not go away on its own" (p. 127). Therefore, a large scale study has to be undertaken to provide more reliable and valid data relating to the prevalence of burnout syndrome amongst teachers in Botswana. Once the research data is available, targeted intervention strategies will be developed to help teachers and other victims of the burnout syndrome.

\section{References}

Aluja, A., Blanch, A., \& Garcia, L. F. (2005). Dimensionality of the Maslach Burnout Inventory in School Teachers: A Study of Several Proposals. European Journal of Psychological Assessment , 21(1), 67-76. https://www/10.1027/1015-5759.21.1.67

Baliyan, S.P., Baliyan, P.S., \& Mokoena, S. (2018). Occupational Stress among Teachers in Private Senior Secondary Schools in Botswana: Causes and Consequences. International Journal of Education, 10(2), 32-49. https://www/10.5296/ije.v10i2.13085

Bevis, Kimberly A. (2008). Teacher burnout: Locus of control and its correlation to teacher burnout and job satisfaction. Retrieved from https://mds.marshall.edu/cgi/viewcontent.cgi?article=1466\&context=etd

Bitsadze, M., \& Japaridze, M. (2016). Locus of control in Georgian teachers and its relation 
to teacher burnout. Problem of Management in the $21^{\text {st }}$ Century, 11(201), 8-15. http://www.scientiasocialis.1t/pmc/files/pdf/8-15.Bitsadze Vol.11-1 pmc.pdf

Brasfield, M. W., Lancaster, C., and Xu, Y. J. (2019). Wellness as a mitigating factor for teacher burnout. Journal of Education 2019, 199(3) 166-178. https://doi.org/10.1177/0022057419864525

Brissie, J. S., Hoover-Dempsy, K. V., \& Bassler, O. C. (1988). Individual and situational contributors to teacher burnout. Journal of educational research, 82(2), 106-112. https://www/doi.org/10.1080/00220671.1988.1088587

Byrne, B. M. (1991). The Maslach Burnout Inventory: Validating factorial structure and invariance across intermediate, secondary, and university educators. Multivariate Behavioural Research, 26, 477-499.

Byrne, B. M. (1993). The Maslach Burnout Inventory: Testing for factorial validity and invariance across elementary, intermediate and secondary teachers. Journal of Occupational and Organizational Psychology, 66, 197-212.

Byrne, B. M. (1994). Burnout: Testing for the validity, replication, and invariance of causal structure across elementary, intermediate, and secondary teachers. American Educational Research Journal, 31, 645-673. https://www/doi.org/10.3102/00028312031003645

Burns, L. K. (2016), Perceived organizational support and perceived supervisor support as antecedents of work engagement. Unpublished Master's Theses. San Jose State University, USA.

Cattell, R.B. (1978). The scientifi c use of factor analysis. New York: Plenum.

Capel, S. A. (1987). The incidence of and in uences on stress and burnout in secondary school teachers. British Journal of Educational Psychology, 57, 279-288.

Chang, M.-L. (2009). An appraisal perspective of teacher burnout: Examining the emotional work of teachers. Educational Psychology Review, 21, 193. https://www/10.1007/s10648-009-9106-y

Comrey, A. L., \& Lee, H. B. (1992). A first course in factor analysis $\left(2^{\text {nd }}\right.$ ed.). Hillsdale, $\mathrm{Nj}$ : Erlbaum.

Dorman, J. (2003). Testing a model for teacher burnout. Australian Journal of Educational and Developmental Psychology, 3, 35-47. https://www-test.newcastle.edu.au/data/assets/pdffile/0020/100487/v3-dorman.pdf

Dubale, B. W., Friedman, L. E., Chemali, Z., Denninger, J. W., Mehta,D. H.,Alem, A., Fricchione, G, L., Dossett, M. D., and Gelaye, B. (2019) Systematic review of burnout among healthcare providers in sub-Saharan Africa. BMC Public Health. https://doi.org/10.1186/s12889-019-7566-7

Farber, B. A. (1984). Stress and Burnout in Suburban Teacher. The Journal of Educational Research, 77 (6), 325-331. https://www/doi.org/10.1080/00220671.1984.10885550

Firth, H., McIntee, J., McKeown, P., \& Britton, P. G. (1985). Maslach Burnout Inventory: Factorstructure and norms for British nursing staff. Psychological Reports, 57, 147-150.

Goddard, R. , \& Goddard, M. (2006). Beginning Teacher Burnout in Queensland Schools: Associations with Serious Intentions to Leave. The Australian Educational Researcher, 33(2).

Gold, Y., Bachelor, P., \& Michael,W.B. (1989). The dimensionality of a modified form of the Maslach Burnout Inventory for university students in a teacher-training program. Educational and Psychological Measurement, 49, 549-561.

Gold, Y. (1984). The factorial validity of the Maslach Burnout Inventory in a sample of California elementary and junior high school classroom teachers. Educational and Psychological Measurement, 44, 1009-1016.

Green, D. E., \& Walkey, F. H. (1988). A confirmation of the three-factor structure of the Maslach Burnout Inventory. Educational and Psychological Measurement, 48, 579-585.

Holland, P.J., Michael,W.B.,\& Kim, S. (1994). Construct validity of the Educator Survey for a sample of middle school teachers. Educational and Psychological Measurement, 54, 822-830.

Isaiah, M. N., \& Nenty, H J. (2012). Predicting job dissatisfaction among community junior secondary school teachers in Botswana. Psychology, 3 (3). 277-283. http://dx.doi.org/10.4236/psych.2012.33039

Iwanicki, E. F., \& Schwab, R. L. (1981). A cross validation study of the Maslach Burnout Inventory. Educational and Psychological Measurement, 41(4), 1167-1174. https://www/doi.org/10.1177/001316448104100425

Jacobson, D. (2016). Causes and Effects of Teacher Burnout. Unpublished doctoral 
dissertation,

Walden

University.

https://scholarworks.waldenu.edu/cgi/viewcontent.cgi?article $=3938 \&$ context $=$ dissertations

Jackson, L. T. B., \& Rothman, S. (2005). An adapted model of burnout for educators in South Africa. South African Journal of Education, 25(2). 100-108. http://www.ianrothmann.com/pub/educat v25 n2 a7.pdf

Johnson, S., Cooper, C., Cartwrights, S., Donald, I., Taylor, P., \& Millet, C. (2005). The experience of work-related stress across occupations. Journal of Managerial Psychology, 20, 178-187, https://www/doi.org/10.1108/02683940510579803

Kaiser, H.F. (1960). The application of electronic computers to factor analysis. Educational and Psychological Measurement, 20, 141-151.

Kerry-Henkel, L. A. (2017). Teacher burnout, self-efficacy, and the identification and referral of at-risk students. Unpublished doctoral dissertation, University of Arizana. https://repository.arizana.edu/bitsream/handle/10150/625274/azu

Kim, L. E., Jörg, V., \& Klassen, R. M. (2019). A Meta-Analysis of the Effects of Teacher Personality on Teacher Effectiveness and Burnout. Educational Psychology Review, 3, 163-195. https://doi.org/10.1007/s10648-018-9458-2

Kormanik, M., \& Rocco, T. (2009). Internal versus external control of reinforcement: A review of the locus of control construct. Human Development Review, 8, 436-483 https://www/doi.org/10.1.1.892.6666\&re=1\&type=pdf

Leiter, M. P., \& Maslach, C. (1988). The impact of interpersonal environment on burnout and organizational commitment. Journal of Organizational Behavior, 9, 297-308.

Li, Shen., Li, Yibo., Lv, Hao., Jiang, Rui., Zhao, Peng., Zheng, Xin., Wang, Lili., Li, Jie., \& Mao, Fuqiang. (2020). The prevalence and correlates of burnout among Chinese preschool teachers. $B M C$ Public Health, 20 (160). https://doi.org/10.1186/s12889-020-8287-7

Louw, D. A., George, E., \& Esterhuyse, K. (2011). Burnout amongst urban secondary school teachers in Namibia. SA Journal of Industrial Psychology/SATydskrif vir Bedryfsielkunde, 37(1), 1-7. https://www/doi.org/10.4102/sajip.v37i1.1008

Larrivee, B. (2012). Cultivating teacher Renewal: guarding against stress and burnout. United Kingdom: Rowman and Littlefield Education.

Lunenburg, F., \& Cadavid, V. (1992). Locus of control, pupil control ideology, and dimensions of teacher burnout. Journal of Instructional Psychology 19(1). https://files.eric.ed.gov/fulltext/ED333560.pdf

Maslach, C., \& Jackson, S. E. (1981). The measurement of experienced burnout. Journal of Occupational Behaviour, 2, 99-113. https://ww/doi.org/10.1002/job.4030020205

Maslach, C., Jackson, S. E., \& Schwab, R. L. (1996). Maslach Burnout Inventory-Educators Survey. Palo Alto, CA: Mind Garden.

Maslach, C., Schaufeli, W., \& Leiter, M. (2001). Job burnout. Annual Reviews Psychology, 52, 397-422. https://www/doi.org/10.1146/annurev.psych.52.1.397

O’Brien, P., Goddard, R., \& Keeffe, M. (2008, November). Burnout confirmed as a viable explanation for beginning teacher attrition. Proceedings from the Australian Association for Research in Education Annual Conference 2007 (pp. 25-29).Research Fremantle, Australia. https://eprints.usq.edu.au/3813/2/O\%27Brien_Goddard Keefe ARE 2007 PV.pdf

Okwaraji F. E., \& Aguwa, E. N. (2015). Burnout, psychological distress and job satisfaction among secondary school teachers in Enugu, South East Nigeria. Journal Psychiatry 18(1). 14-66. https://doi.org/10.4172/Psychiatry.1000198

Pheko, B.C., Mosothwane, M., \& Segomotsi, P. (2015). Factors associated with teacher burnout in some Gaborone secondary schools in Botswana. Journal of Education and Practice, 6(36), 186-198. https://pdfs.semanticscholar.org/7c5f/5c88a1cc15c5c73278a40217c2d468ef81dc.pdf

Polatcan, M., Cansoy R., \& Kılınç, A. Ç. (2019). Examining empirical studies on teacher burnout: A systematic review. Hacettepe University Journal of Education. 1-19. https://www/10.16986/HUJE.2019054890

Riketta, M. (2005). Organizational identification: A meta-analysis. Journal of Vocational Behavior, 66, 358-384.

Russell, D.W., Altmaier, E., and Van Velzen, D. (1987). ,"Job-Related Stress, Social Support and Burnout Among Classroom Teachers", Journal of Applied Psychology, 72 (2), 269-274. 
Sarros, J. C., \& Sarros, A. M. (1987). Predictors of teacher burnout. Journal of Educational Administration, 25 (2), 216-230. https://doi.org/10.1108/eb009933

Scott, S. B. (2019). Factors influencing teacher burnout and retention strategies. Honors Research Projects.798. https://ideaexchange.uakron.edu/honors_research_projects/798

Skaalvik, E. M., Skaalvik, S. (2007). Dimensions of Teacher Self-efficacy and Relations with Strain Factors, Perceived Collective Teacher Efficacy, and Teacher Burnout. Journal of Educational Psychology, 99(3), 611-625. http://dx.doi.org/10.1037/0022-0663.99.3.611

Skaalvik, E. M., \& Skaalvik, S. S. (2010). Teacher self-efficacy and teacher burnout: A study of relations. Teaching and Teacher Education, 26(4), 1059-1069. http://www./doi.org/10.1016/i.tate.2009.11.001

Smetackovaa, I. (2019). Self-efficacy and burnout syndrome among teachers. The European Journal of Social and Behavioural Sciences. 20. 2476-2488. http://dx.doi.org/10.15405/ejsbs.219

Tosi, H. \& Tosi, D. (1970). Some correlates of role conflict and role ambiguity among public school teachers. Journal of Human Relations, 18, 1068-1076

Tsigilis, N., Zournatzi, E., and Koustelios, A. (2011).. Burnout among physical education teachers in primary and secondary schools. International Journal of Humanities and Social Science, 1(7), https://www.semanticscholar.org/paper/Burnout-among-physical-education-teachers

Uzun, T. (2018). A study of correlations between perceived supervisor support, organizational identification, organizational citizenship behavior, and burnout at schools. European Journal of Educational Research, 7(3), 501-511. https://www/doi.org/10.12973/eu-jer.7.3.501

Van Tonder, C.L., \& Williams, C. (2009). Exploring the origins of burnout among secondary educators. SA Journal of Industrial Psychology, 35(1),204-218. https://www/10.4102/sajip. v35i1.762

Van Zyl, K. (2015). Burnout in Special Needs Educators in Pietermaritzburg: Associations with Intentions to Leave. https://researchspace.ukzn.ac.za/bitstream/handle/10413/14195/

Weiskopf, P. E. (1980). Burnout among teachers of exceptional children. Exceptional Children, 47, 18-23. 